\title{
Current AATS guidelines on surgical treatment of infective endocarditis
}

\author{
Gösta B. Pettersson ${ }^{1}$, Syed T. Hussain ${ }^{2}$ \\ ${ }^{1}$ Department of Thoracic and Cardiovascular Surgery, Cleveland Clinic, Cleveland, OH, USA; ${ }^{2}$ Department of Cardiovascular and Thoracic Surgery, \\ Northwell Health/Southside Hospital, Bay Shore, NY, USA \\ Correspondence to: Gösta B. Pettersson, MD, PhD. Department of Thoracic and Cardiovascular Surgery, Cleveland Clinic, 9500 Euclid Avenue/Desk \\ J4-1, Cleveland, OH, USA. Email: petterg@ccf.org.
}

The 2016 American Association for Thoracic Surgery (AATS) guidelines for surgical treatment of infective endocarditis (IE) are question based and address questions of specific relevance to cardiac surgeons. Clinical scenarios in IE are often complex, requiring prompt diagnosis, early institution of antibiotics, and decisionmaking related to complications, including risk of embolism and timing of surgery when indicated. The importance of an early, multispecialty team approach to patients with IE is emphasized. Management issues are divided into groups of questions related to indications for and timing of surgery, pre-surgical work-up, preoperative antibiotic treatment, surgical risk assessment, intraoperative management, surgical management, surveillance, and follow up. Standard indications for surgery are severe heart failure, severe valve dysfunction, prosthetic valve infection, invasion beyond the valve leaflets, recurrent systemic embolization, large mobile vegetations, or persistent sepsis despite adequate antibiotic therapy for more than 5-7 days. The guidelines emphasize that once an indication for surgery is established, the operation should be performed as soon as possible. Timing of surgery in patients with strokes and neurologic deficits require close collaboration with neurological services. In surgery infected and necrotic tissue and foreign material is radically debrided and removed. Valve repair is performed whenever possible, particularly for the mitral and tricuspid valves. When simple valve replacement is required, choice of valve-mechanical or tissue prosthesis-should be based on normal criteria for valve replacement. For patients with invasive disease and destruction, reconstruction should depend on the involved valve, severity of destruction, and available options for cardiac reconstruction. For the aortic valve, use of allograft is still favored.

Keywords: AATS guidelines; infective endocarditis; native valve endocarditis; prosthetic valve endocarditis

Submitted Jul 25, 2019. Accepted for publication: Aug 08, 2019.

doi: $10.21037 /$ acs.2019.10.05

View this article at: http://dx.doi.org/10.21037/acs.2019.10.05

\section{Introduction}

Infective endocarditis (IE) is the most severe and potentially devastating complication of heart valve disease, be it native valve endocarditis (NVE), prosthetic valve endocarditis (PVE), or infection on another cardiac device (1-6). An increasingly elderly population with degenerative heart valve disease and an increase in staphylococcal infections have contributed to an increase in the prevalence of IE in the last 30 years. An increasing number of patients undergo heart surgery or receive prosthetic valves, pacemakers, and defibrillators, all factors associated with increased risk of IE.

Without treatment, IE is almost uniformly fatal. Even at experienced centers, operations for IE remain associated with the highest mortality of any valve disease (1-12). Multicenter studies still report in-hospital mortality of $15-20 \%$ and 1 -year mortality approaching $40 \%$ (1-13).

Caring for patients with IE requires a team of physicians with expertise in various aspects of the disease. The American Association for Thoracic Surgery (AATS) guidelines address questions relevant and important to cardiac surgeons before, during, and after operation: when 
to operate, how to prepare the patient for operation, how to operate, and other issues relevant to management and follow up of patients after surgery (1-6). The focus of the 2016 guidelines is active and suspected IE affecting valves and intracardiac structures and management of concomitant device infections. Management of isolated infections of devices, including pacemakers, defibrillators, ventricular assist devices, and others is not addressed.

Because the clinical scenarios presented by patients with IE are most often complex $(14,15)$, their successful management requires a multispecialty team approach. As the role of surgery and early surgery is expanded, the surgeon should be part of the management team from the beginning. This has also been emphasized in the most recent 2015 ACC/AHA guidelines, and the European Society of Cardiology (ESC) guidelines, which recommend that patients with IE should be managed at reference centers by a specialized "endocarditis team" $(2,3)$. The format of AATS consensus guidelines allows the breakdown of complex management questions related to IE into relevant clinical questions. In the following sections, we will review the 2016 AATS consensus guidelines for surgical treatment of IE. Both authors of this review were members of the writing committee for the 2016 AATS endocarditis guidelines (1).

\section{Pathophysiology and microbiology of IE}

The key to understanding IE is appreciating the pathologic progression (16). Circulating organisms, bacteria or other, adhere to damaged areas of the endocardium, (valves, ventricular septal defects), endothelium (patent ductus), or foreign material exposed in the bloodstream (prosthetic heart valves, pacemaker leads). Such damaged areas are sites for development of vegetations. Vegetations are the main source of embolization. The organisms produce and release enzymes that disintegrate tissue, primarily valve cusps and leaflets, resulting in leaky valves. When tissue integration involves the valve annulus, the infection invades the extravascular areas; "invasive disease". Causative microorganism/pathogen, position (aortic, mitral, or rightsided), and type of infected valve (native or prosthetic) are important for pathology and prognosis $(10,11,16)$. Bacteria and fungi have a species-specific repertoire of virulence factors that allow them to establish and maintain IE. Staphylococci and streptococci are the most common, aggressive, and destructive bacteria. Severity of invasion and destruction seems to be a function of virulence and time, with $S$ aureus being most aggressive and destructive.
Emboli from vegetations cause stroke, mycotic aneurysms, and related phenomena. Toxins and enzymes cause tissue disintegration and invasion resulting in valve regurgitation, fistulas, paravalvular abscesses, and heart block. Valves made regurgitant by bacterial destruction will continue to leak even if the infection is ultimately eradicated. Disease stage at diagnosis is related to pathogen virulence and disease duration.

Systemic emboli are common in patients with leftsided IE. Embolic strokes, with or without hemorrhagic conversion, are frequent and clinically important (2-4). Although less common, systemic septic emboli can cause mycotic aneurysms in any artery, including the aorta. Rightsided IE frequently showers the lungs with septic emboli, leading to pulmonary abscesses and empyema. Right-sided IE can also be responsible for systemic emboli in patients with patent foramen ovale.

The microbiology of IE varies depending on whether the valve is native or prosthetic, and whether the infection is community acquired or healthcare associated. Staphylococci, streptococci, and enterococci are responsible for approximately $85 \%$ of all IE, with staphylococci and streptococci being the most common aggressive and destructive bacteria causing IE. Fungi form vegetations or balls, but are usually less invasive, although they can lead to development of mycotic aneurysms and easily become disseminated.

All patients diagnosed with IE are first treated with antimicrobials, initially broad spectrum, and then adjusted to the sensitivity pattern once it is known. Antimicrobials to which the organisms are sensitive clear the bacteremia, may or may not prevent or halt further destruction, and may, if initiated early enough cure the infection $(2-4,6)$. Cure of the infection will not restore integrity of damaged valves or repair invasive disease. Taking advantage of the operative specimens for cultures and sequencing of operative specimens can help identify the causative microorganism.

The hypothesis that IE is a biofilm-associated infection offers plausible explanations as to why IE related infections are difficult to treat, why recurrence may occur after seemingly successful medical treatment, and why surgery is often required. Biofilm-producing bacterial populations live embedded in a self-produced extracellular polysaccharide slime-like matrix protecting them from the host's immune defenses and impedes antimicrobial efficacy (17). Capacity for biofilm production is a hallmark of microorganisms that commonly cause IE, including staphylococci, streptococci, and enterococci. Surgery not only removes infected 


\begin{tabular}{|c|c|c|}
\hline Recommendations & COR & LOE \\
\hline \multicolumn{3}{|l|}{ 1. Who should care for and operate on patients with IE? } \\
\hline $\begin{array}{l}\text { Patients with suspected IE should ideally be cared for at centers with access to a complete team, including cardiology, } \\
\text { infectious disease, cardiac surgery, and other services needed to handle IE complications }\end{array}$ & 1 & B \\
\hline $\begin{array}{l}\text { Surgeons operating on patients with IE should be well-trained, experienced valve surgeons who are well versed in the } \\
\text { different reconstruction techniques needed by patients with advanced disease }\end{array}$ & 1 & C \\
\hline \multicolumn{3}{|l|}{ 2. Diagnosis of IE: What does the surgeon need to know? } \\
\hline $\begin{array}{l}\text { At the time of surgery the patient should be on an effective antimicrobial regimen (correct dosage and route of administration) } \\
\text { to which the causative microorganism is sensitive, or be broadly covered when organism and sensitivity are unknown }\end{array}$ & 1 & B \\
\hline $\begin{array}{l}\text { For surgery planning, the surgeon should have the best possible understanding of the pathology. This will usually require } \\
\text { advanced imaging techniques, such as TEE }\end{array}$ & 1 & B \\
\hline
\end{tabular}

Figure 1 Team approach to patients with IE. Reproduced from Pettersson GB, Coselli JS, Hussain ST, et al. 2016 American Association for Thoracic Surgery (AATS) Consensus Guidelines: Surgical Treatment of Infective Endocarditis. 7 Thorac Cardiovasc Surg 2017;153:12411258.e29, with permission from Elsevier.

tissue and foreign material, but also mechanically disrupts the biofilm and exposes residual live microorganisms to antimicrobials, antibodies, and immune cells. In addition, the surgeon restores valve function and cardiac integrity. Surgery is, however, always followed by a full course of intravenous antimicrobial therapy for cure.

PVE is generally more invasive than NVE and more difficult to cure with antibiotics alone. Biofilm formation represents a biological basis for the more frequent need for surgery in PVE. Comparing aortic to mitral valve IE, aortic valve IE is more often invasive (both aortic NVE and PVE) (10). Despite this, outcomes are worse after surgical treatment of mitral valve IE than aortic valve IE (10). Three important factors contribute to this: (I) mitral valve IE patients are sicker with more comorbidities; (II) for invasive IE, the surgical anatomy of mitral valve IE is less favorable; and (III) no allograft valve alternative for severe invasive disease currently exists for the mitral valve. Right-sided IE typically is less invasive, although it is more often caused by aggressive organisms, including $S$ aureus, than left-sided IE.

In the following segment, the specific recommendations are reviewed as per Figures and themes in the guideline document (1).

\section{AATS guidelines themes and questions}

\section{Team approach for patients with IE (Figure 1) $(2-4,6,8,18,19)$}

Patients with suspected IE should ideally be referred early to centers with access to a complete team, including cardiology, infectious disease, cardiac surgery, and services needed to handle IE-related complications (e.g., neurology, psychiatry, and nephrology). Surgical input should be solicited early in the evaluation. Surgeons operating on patients with IE need to be well-trained, experienced valve surgeons well versed in the different reconstruction techniques needed by patients with advanced disease.

\section{Diagnosis of IE and essentials for surgical planning (Figure 1)}

Diagnosis of IE is based on clinical symptoms, physical findings, microbiology results, echocardiography, and other studies. Duke or modified Duke criteria are used to classify certainty of the diagnosis $(14,15)$. A transthoracic echocardiogram (TTE) must be supplemented with TEE in most cases of suspected prosthetic IE. A TEE should be considered early when organisms with a high likelihood of pyogenic complications are implicated or when there is a question about the presence or absence of valve infection based on the quality of the TTE images. Use of imaging modalities other than echocardiography may be appropriate in selected cases. Electrocardiogramgated CT has comparable diagnostic performance to TEE and may be a valuable complement in the preoperative evaluation of patients with aortic PVE. Multidetector CT (MDCT) can be used to detect abscesses/pseudoaneurysms with a diagnostic accuracy similar to TEE, and is possibly 
superior in providing information about the extent of any perivalvular extension, including the anatomy of pseudoaneurysms, abscesses, and fistulas. Other diagnostic modalities like single-photon emission computed tomography (SPECT)-CT imaging with radiolabeled leukocytes and 18F-fluorodeoxyglucose (FDG) PET-CT imaging can be useful in securing the diagnosis, and in detection of peripheral embolic and metastatic infectious events.

When going to the operating room, the patient should be on an effective antimicrobial regimen when organism and sensitivity are known, or be broadly covered when these unknown.

For surgical planning, it is imperative for the surgeon to carefully review the echocardiograms and other imaging studies to better understand the pathology and stage of the disease for appropriate surgical planning. However, it is important to remember that even TEE is not necessarily perfectly accurate, particularly in patients with mechanical valves.

\section{Indications for and timing of surgery for patients with IE (Figure 2) (2-6,10-13,20-32)}

The AATS recommendations, although similar, are not identical to the ACC/AHA recommendations $(2,4)$. Minor changes and nuances have been added. Surgical treatment should be considered in patients with signs of heart failure, severe valve dysfunction, prosthetic PVE, invasion with paravalvular abscess or cardiac fistulas, recurrent systemic embolization, large mobile vegetations, and persistent sepsis despite adequate antibiotic therapy for more than 5 to 7 days. Factors related to complications, primarily neurologic and comorbidities, must be considered and weighed in the decision-making process $(2,4)$. The AATS guidelines emphasize that reason and timing of surgery cannot be separated but must be seen in relation to each other. The final decision to operate should be a consensus decision by the treating team.

The main disagreement relates to the level of aggressiveness and definition of early surgery. Approximately half of patients with IE develop severe complications that sooner or later require operation. The AATS guidelines conclude that once a surgical indication is evident, surgery should not be delayed. In patients with NVE, waiting for heart failure symptoms in a patient with severe valve regurgitation and vegetations does not offer any benefit. Studies by Kang et al. and by many other experienced groups recommend operating before heart failure has developed (13). In Kang's study, the most frequent complication in the conventional treatment group was embolic stroke.

Patients with invasive staphylococcal PVE and early PVE require early surgery. Delaying surgery allows the destruction to progress and increases the risk of heart block and embolism. For patients with uncomplicated, nonstaphylococcal, and late PVE, treatment with antibiotics alone may be worth trying, but often the infection recurs within a few months.

Surgery during initial hospitalization before completion of a full therapeutic course of antibiotics is indicated in patients with IE who present with valve dysfunction and heart failure symptoms, patients with left-sided IE caused by $S$. aureus, fungal or other highly resistant microorganisms, or patients with evidence of persistent infection as manifested by persistent bacteremia or fever lasting longer than 5 to 7 days after initiation of appropriate antimicrobial therapy (1-5).

AATS guidelines recommend urgent or even emergency surgery in patients with left-sided NVE or PVE who exhibit mobile vegetations greater than $10 \mathrm{~mm}$ in length with clinical evidence of embolic phenomenon despite appropriate antibiotic therapy. Large mobile vegetationsgreater than $10 \mathrm{~mm}$ on the anterior mitral valve leaflethave been proven to be associated with higher embolic risk $(8,13)$. Location, size, and mobility of the vegetation, previous embolism, type of organism, and duration of antimicrobial therapy all influence the associated risk of another embolic event. The trend is to be more aggressive and operate on patients at imminent risk of embolism earlier. The additional risk of operating on patients with active IE is low and when the indication is large vegetations and risk of embolism, it is frequently possible to preserve the valve, more often so for the mitral than the aortic valve. A recurrent embolic event may occur at any point and may be devastating.

The general indications discussed above may or may not be applicable to right-sided IE. When multiple valves, left- and right-sided, are infected, the indication for surgery is usually decided by the left-sided IE. In right-sided IE, indications for surgery are most often failure to control the infection and septic pulmonary embolism, and less often tricuspid valve regurgitation in itself. One consequence of pulmonary embolism is increasing pulmonary vascular resistance and reduced ability to tolerate valve regurgitation, resulting in congestion and right-heart failure symptoms. 


\begin{tabular}{|c|c|c|}
\hline Recommendations & COR & LOE \\
\hline \multicolumn{3}{|l|}{ 1. What are the indications for surgery in patients with IE? } \\
\hline $\begin{array}{l}\text { Surgery during initial hospitalization independently of the completion of a full therapeutic course of antibiotics is } \\
\text { indicated in patients with IE who present with valve dysfunction resulting in symptoms of heart failure }\end{array}$ & 1 & B \\
\hline $\begin{array}{l}\text { Surgery during initial hospitalization independently of the completion of a full therapeutic course of antibiotics is } \\
\text { indicated in patients with left-sided IE caused by } S \text {. aureus, fungal, or other highly resistant microorganisms }\end{array}$ & 1 & B \\
\hline $\begin{array}{l}\text { Surgery during initial hospitalization independently of completion of a full therapeutic course of antibiotics is indicated } \\
\text { in patients with IE complicated by heart block, anular or aortic abscess, or destructive penetrating lesions }\end{array}$ & I & B \\
\hline $\begin{array}{l}\text { Surgery during initial hospitalization independently of completion of a full therapeutic course of antibiotics for IE is } \\
\text { indicated in patients with evidence of persistent infection as manifested by persistent bacteremia or fever lasting longer } \\
\text { than } 5 \text { to } 7 \text { days after initiation of appropriate antimicrobial therapy }\end{array}$ & I & B \\
\hline $\begin{array}{l}\text { Surgery is recommended for patients with PVE and relapsing infection (defined as recurrence of bacteremia after a } \\
\text { complete course of appropriate antibiotics and subsequently negative blood cultures) without other identifiable source } \\
\text { for portal of infection }\end{array}$ & Ila & $\mathrm{C}$ \\
\hline $\begin{array}{l}\text { Surgery during initial hospitalization independently of the completion of a full therapeutic course of antibiotics is } \\
\text { reasonable in patients with IE who present with recurrent emboli and persistent vegetations despite appropriate } \\
\text { antibiotic therapy }\end{array}$ & Ila & B \\
\hline $\begin{array}{l}\text { Urgent or even emergency surgery may be considered in patients with NVE or PVE who exhibit mobile vegetations } \\
\text { greater than } 10 \mathrm{~mm} \text { in length with clinical evidence of embolic phenomena despite appropriate antimicrobial treatment }\end{array}$ & Ilb & B \\
\hline $\begin{array}{l}\text { In patients with right-sided IE, surgery should be considered for NVE or PVE when large vegetations are present and } \\
\text { there is evidence of persistent infection manifested by persistent bacteremia or fevers lasting longer than } 5 \text { to } 7 \text { days } \\
\text { after initiation of appropriate antimicrobial therapy, or in those with evidence of septic pulmonary embolism }\end{array}$ & Ilb & B \\
\hline \multicolumn{3}{|l|}{ 2. When should the patient undergo operation? } \\
\hline Once an indication for surgery is established, the patient should be operated on within days & I & B \\
\hline $\begin{array}{l}\text { Earlier surgery (emergency or within } 48 \text { hours) is reasonable for patients with large mobile vegetations at imminent risk } \\
\text { of embolism }\end{array}$ & Ila & B \\
\hline $\begin{array}{l}\text { In patients with stroke and neurologic deficits, timing is decided by weighing the need for cardiac surgery against } \\
\text { the risk of expanding the stroke or provoking intracranial bleeding during the operation (see specific question about } \\
\text { neurologic complications) }\end{array}$ & Ila & B \\
\hline
\end{tabular}

Figure 2 Indications for and timing of surgery for patients with IE. Reproduced from Pettersson GB, Coselli JS, Hussain ST, et al. 2016 American Association for Thoracic Surgery (AATS) Consensus Guidelines: Surgical Treatment of Infective Endocarditis. 7 Thorac Cardiovasc Surg 2017;153:1241-1258.e29, with permission from Elsevier.

As per the AATS guidelines, in patients with right-sided IE, surgery should be considered for NVE or PVE when large vegetations are present (large for right side defined as $>20 \mathrm{~mm}$ ) and the patient has persistent bacteremia or fevers lasting longer than 5 to 7 days after initiation of appropriate antimicrobial therapy, or in those with evidence of septic pulmonary embolism $(3,6,18,19)$.

Early surgery is defined as surgery "during initial hospitalization independent of completion of a full therapeutic course of antibiotics." $(2,4)$. Surgery undertaken for the prevention of embolism is mainly relevant early, during the first few days after initiating antimicrobial therapy (emergency or urgent). Risk of embolism is highest during the first two weeks of antibiotic therapy and is clearly related to size and mobility of the vegetations, although other risk factors exist. The risk of stroke in IE falls dramatically each day after initiation of effective antimicrobial therapy. Reduction in size of vegetations with appropriate antimicrobial therapy also appears to be associated with reduced embolic risk.

As per the AATS guidelines, once an indication for surgery is established, the patient should be operated on within days, and earlier surgery (emergency or within 48 hours) is reasonable for patients with large mobile vegetations at imminent risk of embolism $(2-5,12,21,33,34)$. In patients with stroke and neurologic deficits, timing is decided by weighing the need for cardiac surgery against the risk of expanding the stroke or provoking intracranial 


\begin{tabular}{|c|c|c|}
\hline Recommendations & COR & LOE \\
\hline \multicolumn{3}{|c|}{$\begin{array}{l}\text { 1. What is the effect of neurologic complications, embolic stroke, brain hemorrhage, and mycotic aneurysm on indication for and timing } \\
\text { of surgery? }\end{array}$} \\
\hline $\begin{array}{l}\text { If a cerebral mycotic aneurysm has been diagnosed, treatment and follow-up of the patient should be in close collaboration } \\
\text { with neurologic and neurosurgery expertise }\end{array}$ & 1 & C \\
\hline In patients with a recent intracranial hemorrhage, a delay of operation for 3 or more weeks is reasonable & Ila & B \\
\hline Earlier surgery is reasonable for patients with non-hemorrhagic strokes and a strong cardiac indication for urgent surgery & Ila & B \\
\hline $\begin{array}{l}\text { Patients with large and multiple strokes and severe neurologic symptoms should be carefully evaluated by a neurologist } \\
\text { before being offered surgery }\end{array}$ & 1 & B \\
\hline $\begin{array}{l}\text { For patients with IE and neurologic symptoms and significant intracranial hemorrhage, angiography should be considered to } \\
\text { rule out mycotic aneurysm }\end{array}$ & Ila & B \\
\hline Endocarditis patients with neurologic symptoms should have brain imaging & 1 & B \\
\hline $\begin{array}{l}\text { It is reasonable to screen patients with left-sided IE for possible stroke or intracranial bleeding before operation, particularly } \\
\text { if they have cardiac lesions considered high risk for embolic events }\end{array}$ & Ila & B \\
\hline \multicolumn{3}{|c|}{$\begin{array}{l}\text { 3. What workup is needed for diagnosing primary infectious focus, secondary manifestations and complications (other than neurologic), } \\
\text { and satellite infections in patients with IE? }\end{array}$} \\
\hline $\begin{array}{l}\text { Patients with IE should be screened for primary non-cardiac focus of infection, non-cardiac complications, and satellite } \\
\text { infections: The choice of diagnostic procedure (e.g., CT, MRI, ultrasonography) varies, and the selection should be } \\
\text { individualized for each patient based on clinical symptoms and suspicions }\end{array}$ & 1 & C \\
\hline \multicolumn{3}{|l|}{ 4. How should anticoagulation in patients with IE, with and without stroke or intracranial bleeding, be managed? } \\
\hline $\begin{array}{l}\text { Anticoagulation management in patients who have compelling indications for anticoagulation, e.g., atrial fibrillation, } \\
\text { mechanical prosthetic valve, deep vein thrombosis, or pulmonary embolism, has to seek compromises, taking all risks and } \\
\text { benefits into consideration }\end{array}$ & 1 & $\mathrm{C}$ \\
\hline
\end{tabular}

Figure 3 Pre-surgical work-up and management of patients with IE. Reproduced from Pettersson GB, Coselli JS, Hussain ST, et al. 2016 American Association for Thoracic Surgery (AATS) Consensus Guidelines: Surgical Treatment of Infective Endocarditis. 7 Thorac Cardiovasc Surg 2017;153:1241-1258.e29, with permission from Elsevier.

bleeding during the operation (2-5,20-27,31-36).

\section{Presurgical work-up and management of patients with IE (Figure 3)}

\section{Neurologic complications and role of brain imaging in patients with IE (2-4,20-24,33-40)}

IE patients with neurologic symptoms scheduled for surgery should have a neurologic evaluation by a neurologist, and brain imaging, either by CT or MRI, within days of the planned operation to visualize any strokes and to determine if an infarct is ischemic or hemorrhagic. Routine preoperative screening of asymptomatic patients, particularly those with high-risk vegetations, is justified. The neurologic symptoms, consciousness, location and size of infarct, type (primary or hemorrhagic conversion in infarct), location, size, and timing of hemorrhage, and risk and probability of mycotic aneurysm are all factors to consider when deciding on further imaging, operative risk, and timing of surgery. The standard recommendation is to delay surgery for 1 to 2 weeks in patients with nonhemorrhagic strokes, and for 3 to 4 weeks in patients with hemorrhagic strokes to reduce the risk of further intracranial bleeding during heart surgery. Patients with serious neurologic damage, unconscious patients, and those unable to follow simple commands should not be operated on until neurologic improvement has been demonstrated and potential for recovery has been established. Hemorrhagic lesions are associated with a higher probability of mycotic aneurysms, and these patients need to undergo cerebral angiography to exclude a mycotic aneurysm. Presence of a mycotic aneurysm increases the 
risk of peri- and postoperative bleeding, and the neurologist and neurosurgeon should decide whether to treat and secure the aneurysm before the heart operation.

For those with non-hemorrhagic embolic strokes, the main concerns are worsening the neurologic damage due to hemorrhagic conversion of the infarct and edema during the operation. The risk of worsening neurologic symptoms as a consequence of operation is time related, decreasing with increasing time from the initial neurologic event. If the patient is stable and risk of additional embolism is deemed to be low, delaying surgery for 1 to 2 weeks is probably beneficial, with repeat brain imaging before operation. The risk of worsening the stroke symptoms must be weighed against the indications for surgery and the risk of additional emboli during the waiting period.

Given the high rate of brain embolization detected in patients without clinical neurologic deficits, patients with left-sided IE should be screened by CT or MRI for possible stroke or intracranial bleeding.

\section{Screening for primary infectious focus, non-neurologic complications, and satellite infections in patients with IE (Figure 3)}

Symptoms, specific signs, and causative organism should guide the search for other sources of bacteremia, satellite infections (brain, spine, or splenic abscesses in left-sided IE, pulmonary abscess in right-sided IE) and mycotic aneurysms. The choice of diagnostic modality or procedure (e.g., CT, MRI, ultrasonography) varies, and the selection should be individualized for each patient based on clinical symptoms and suspicions. Imaging with CT or MRI of the chest and abdomen may be justified in select cases, e.g., patients with Aspergillus IE. As per the AATS guidelines, if patients with IE are diagnosed with another infectious focus or abscess (spinal, splenic, or other), the treatment team has to take this finding into consideration and decide timing of intervention for this versus timing of valve surgery.

\section{Anticoagulation in patients with IE, with and without stroke or intracranial bleeding (Figures 2,3)}

Not only is anticoagulation ineffective in preventing septic emboli, being on anticoagulation also increases the risk of hemorrhagic conversion of an ischemic stroke and brain hemorrhage. Anticoagulation management in patients with IE who have compelling indications for anticoagulation, e.g., atrial fibrillation, mechanical prosthetic valve, deep vein thrombosis, or pulmonary embolism, must seek compromises, taking all risks and benefits into consideration.

There are many scenarios in which compromises are preferable, i.e., less anticoagulation rather than more seems safer. If the patient has suffered a stroke, any anticoagulation adds to the risk of hemorrhagic conversion, and if bleeding has already occurred, this risk increases even more. Managing a patient with an infected rocking mechanical valve and intracranial bleeding remains a difficult dilemma.

\section{Additional workup needed just before taking the patient to surgery (Figure 4)}

When the decision has been made to operate on a patient with IE, repeat brain imaging may be needed, depending on new neurologic symptoms, time since the last examination, risk of embolism based on organism, vegetations, and pathology, and whether previous brain imaging demonstrated a stroke or hemorrhage.

Indications for coronary angiography should follow normal criteria for other surgical conditions, particularly if the patient has had coronary artery bypass grafting. In patients with large aortic vegetations, CT angiography is an alternative to assess the coronary arteries.

When repeat sternotomy is required, a preoperative CT of the chest is required to assess the risk of sternal entry. For this purpose, MRI does not provide equally precise information. Contrast is not needed unless there are grafts to be localized as well.

\section{Preoperative duration of antibiotic treatment}

The patient should be on an effective antimicrobial regimen at the time of surgery. The probability of positive cultures from an explanted valve decreases with duration of preoperative treatment and reaches its lowest level after 1 week, with no further improvement. There is no evidence that delaying the surgery to allow a longer period of preoperative treatment is beneficial.

\section{General features of intraoperative management of patients with IE (Figure 5)}

\section{Intraoperative TEE}

Intraoperative comprehensive TEE should be routine because there may be an interval from initial diagnostic imaging to surgery. Upon completion of the operation, another comprehensive echocardiogram should be 


\begin{tabular}{|c|c|c|}
\hline Recommendations & COR & LOE \\
\hline \multicolumn{3}{|l|}{ 1. What additional workup is needed just before taking the patient to surgery? } \\
\hline $\begin{array}{l}\text { When surgery is decided upon, before going to the operating room, it is reasonable to obtain brain imaging or repeat brain } \\
\text { imaging }\end{array}$ & Ila & B \\
\hline $\begin{array}{l}\text { The need for preoperative coronary angiography should be guided by normal criteria. This is particularly important if the } \\
\text { patient has had coronary artery bypass grafting. In patients with large aortic valve vegetations, CT angiography is an } \\
\text { alternative to assess the coronary arteries }\end{array}$ & 1 & C \\
\hline $\begin{array}{l}\text { When repeat sternotomy is required, computed tomography of the chest is recommended when possible to assess risk of } \\
\text { sternal reentry }\end{array}$ & Ila & $\mathrm{C}$ \\
\hline \multicolumn{3}{|l|}{ 2. Is preoperative duration of antibiotic treatment important? } \\
\hline $\begin{array}{l}\text { The patient should be on an effective antimicrobial regimen at the time of surgery. Ideally, the sensitivity of the causative } \\
\text { organism is known }\end{array}$ & I & $\mathrm{B}$ \\
\hline Once the patient is on an effective antimicrobial regimen, further delay of surgery is unlikely to be beneficial & Ila & B \\
\hline \multicolumn{3}{|l|}{ 3. What is the risk of operation for IE? } \\
\hline The patient should be quoted a risk, taking into consideration all factors known to affect the risk of the operation & 1 & C \\
\hline
\end{tabular}

Figure 4 Additional work-up, preoperative antibiotics, and risk of operation for patients with IE. Reproduced from Pettersson GB, Coselli JS, Hussain ST, et al. 2016 American Association for Thoracic Surgery (AATS) Consensus Guidelines: Surgical Treatment of Infective Endocarditis. 7 Thorac Cardiovasc Surg 2017;153:1241-1258.e29, with permission from Elsevier.

performed to detect any important residual pathology or complications, and should be recorded.

\section{Operative approach}

Sternotomy is required for most patients undergoing IE operations, because unexpected findings and discovery of more advanced disease than anticipated are common. Good exposure is required for radical debridement. If unsuspected invasive disease is present, alternate minimally invasive approaches are likely to provide insufficient exposure.

\section{Radical debridement}

All infected material, foreign bodies, and necrotic tissue should be removed to minimize the residual infectious burden and provide optimal access for host defense and antimicrobial therapy. "Radical" does not with wide margins, which may jeopardize valve repair, injure coronaries, cause permanent heart block, and make reconstruction of the heart more difficult. Infected areas are opened and "unroofed", and all infected pockets cleaned out. In patients with PVE, debridement should include removal of the old prosthesis and suture material. In patients with mitral anular calcification, debridement must remove infected calcium but removal must not be so radical that reconstruction is jeopardized. Debridement is followed by generous irrigation. Surgical instruments and gloves should be exchanged after removing all infected tissue and completing irrigation.

General considerations and recommendations for choice of reconstruction and valve replacement (Figures 5,6) (41-49) For NVE, and for the mitral valve in particular, valve repair over replacement is preferred whenever possible $(41,42)$. When simple valve replacement is required, choice of valve-mechanical or tissue prosthesis-should be based on normal criteria: age, life expectancy, comorbidities, and expected compliance with anticoagulation. For patients with invasive disease and destruction, reconstruction should depend on the involved valve, severity of destruction, and available options for cardiac reconstruction

Several studies have suggested that use of an allograft in patients with aortic valve IE is associated with better survival and lower risk of relapse (no early phase of recurrent infection) (43-46). Due to technical difficulty and lack of evidence of superior resistance to reinfection, many surgeons prefer other conduits for reconstruction (44). However, allografts are still used more often in invasive PVE cases (47). In patients who are very sick, have had any intracranial bleeding, or have suffered a major stroke, it is reasonable to avoid use of mechanical prostheses. Using allografts or bioprosthetic valves avoids postoperative anticoagulation, and lowers the risk of hemorrhagic conversion of strokes and other bleeding complications in these patients. 


\begin{tabular}{|c|c|c|}
\hline Recommendations & COR & LOE \\
\hline \multicolumn{3}{|l|}{ 1. Intraoperative TEE } \\
\hline Intraoperative TEE is mandatory when performing surgery for IE & 1 & B \\
\hline Medium sternotomy is the recommended approach, with few exceptions & I & C \\
\hline \multicolumn{3}{|l|}{ 3. Removal of infected tissue: Radical debridement } \\
\hline \multicolumn{3}{|l|}{ 4. Choice of reconstruction and valve replacement: General considerations and recommendations } \\
\hline For patients with NVE and infection limited to the valve cusps or leaflets, repair is performed whenever possible & 1 & B \\
\hline $\begin{array}{l}\text { When simple valve replacement is required, choice of valve-mechanical or tissue prosthesis-should be based on normal criteria: age, } \\
\text { life expectancy, comorbidities, and expected compliance with anticoagulation }\end{array}$ & 1 & B \\
\hline It is reasonable to avoid use of mechanical prostheses in patients with any intracranial bleeding or those who have suffered a major stroke & Ila & C \\
\hline $\begin{array}{l}\text { For patients with native aortic valve IE and infection limited to the valve cusps, repair may occasionally be possible. Choice of } \\
\text { replacement valve-mechanical or tissue prosthesis - should be based on usual criteria }\end{array}$ & 1 & B \\
\hline $\begin{array}{l}\text { For invasive and destructive native aortic valve IE requiring root reconstruction and replacement, using an allograft may be beneficial, } \\
\text { but a prosthetic bioroot or prosthetic valved conduit with a mechanical or bioprosthetic valve are acceptable alternatives, with choice } \\
\text { guided by surgeon training and experience }\end{array}$ & Ila & B \\
\hline \multicolumn{3}{|l|}{ 6. Prosthetic aortic valve IE } \\
\hline $\begin{array}{l}\text { If the root and the anulus are preserved after radical debridement, it is reasonable to implant a new prosthetic valve-mechanical or } \\
\text { tissue-based on normal criteria }\end{array}$ & Ila & B \\
\hline $\begin{array}{l}\text { If there is anulus destruction and invasion outside the aortic root and root reconstruction and replacement is required, an allograft or a } \\
\text { biologic tissue root is preferable to a prosthetic valved conduit }\end{array}$ & Ila & B \\
\hline \multicolumn{3}{|l|}{ 7. Native mitral valve IE } \\
\hline $\begin{array}{l}\text { When there is anulus destruction and invasion, the mitral anulus is reconstructed and the valve prosthesis anchored to the ventricular } \\
\text { muscle or to the reconstruction patch in a way that prevents leakage and pseudoaneurysm development beneath the prosthesis }\end{array}$ & Ila & B \\
\hline \multicolumn{3}{|l|}{ 9. Double-valve IE } \\
\hline $\begin{array}{l}\text { If the aortic root and aortic and mitral anuli are preserved after radical debridement, it is reasonable to implant mechanical or biologic } \\
\text { valves, with the choice based on normal criteria }\end{array}$ & Ila & B \\
\hline $\begin{array}{l}\text { If there is aortic anulus destruction and invasion, and root reconstruction and replacement is required, an allograft or bioroot may be } \\
\text { preferable to a prosthetic valved conduit, and if the mitral anulus shows invasion and destruction, it should be reconstructed to anchor } \\
\text { the valve prosthesis to the ventricular muscle or to the anulus reconstruction patch to avoid leakage and pseudoaneurysm development } \\
\text { beneath the prosthesis }\end{array}$ & Ila & B \\
\hline $\begin{array}{l}\text { Infection destroying the intervalvular fibrosa requires reconstruction of this structure, and it is preferable that surgeons taking on these } \\
\text { cases master such techniques }\end{array}$ & Ila & C \\
\hline \multicolumn{3}{|l|}{ 10. Right-sided IE } \\
\hline The primary objective of surgery for right-sided IE is radical debridement of infected vegetations and foreign material & 1 & B \\
\hline Tricuspid valve repair should be attempted whenever possible & I & $\mathrm{B}$ \\
\hline
\end{tabular}

Figure 5 General features of intraoperative management of patients with IE. Reproduced from Pettersson GB, Coselli JS, Hussain ST, et al. 2016 American Association for Thoracic Surgery (AATS) Consensus Guidelines: Surgical Treatment of Infective Endocarditis. J Thorac Cardiovasc Surg 2017;153:1241-1258.e29, with permission from Elsevier. 


\begin{tabular}{|c|c|c|}
\hline Recommendations & COR & LOE \\
\hline \multicolumn{3}{|l|}{ 1. Should regular synthetic vascular grafts or valveless allografts be used when the aorta must be replaced beyond the root? } \\
\hline $\begin{array}{l}\text { When distal ascending aorta, hemiarch, or arch replacement is required, a synthetic graft is the standard choice, but a } \\
\text { valveless allograft is an alternative in an infected field for replacing the ascending aorta beyond the root }\end{array}$ & Illb & B \\
\hline \multicolumn{3}{|l|}{ 2. Should additional prostheses and vascular grafts not proved to be infected be removed and replaced? } \\
\hline $\begin{array}{l}\text { Inspection and removal of additional prostheses and vascular grafts, even if not proven to be infected, should be considered } \\
\text { and is reasonable if the causative microorganism is } S \text {. aureus or fungus, provided that the added difficulty and risk is not } \\
\text { prohibitive }\end{array}$ & Ila & $\mathrm{C}$ \\
\hline \multicolumn{3}{|l|}{ 3. When should permanent pacemaker systems be removed in patients undergoing surgery for IE? } \\
\hline $\begin{array}{l}\text { Complete removal of pacemaker or defibrillator systems, including all leads and the generator, is indicated as part of the } \\
\text { early management plan in patients with IE and likely infection of the device or leads }\end{array}$ & 1 & B \\
\hline $\begin{array}{l}\text { Complete removal of pacemaker or defibrillator systems, including all leads and the generator, is reasonable in patients } \\
\text { undergoing surgery for valvular IE caused by any organism }\end{array}$ & IIb & $\mathrm{C}$ \\
\hline \multicolumn{3}{|l|}{$\begin{array}{l}\text { 4. Should patients with a known indication for a pacemaker receive a pacemaker system with epicardial leads when undergoing } \\
\text { operation for active IE? }\end{array}$} \\
\hline $\begin{array}{l}\text { At the time of surgery for IE, implantation of a new pacemaker system with epicardial leads may be considered when the } \\
\text { patient is pacer dependent and has effective antimicrobial coverage }\end{array}$ & IIb & $\mathrm{C}$ \\
\hline \multicolumn{3}{|l|}{ 5. Are there any safety concerns regarding use of mechanical valves in patients with IE? } \\
\hline $\begin{array}{l}\text { Mechanical valves should be avoided in patients with IE and evidence of intracranial bleeding or large brain infarcts, and in } \\
\text { patients who are very sick and anticipated to have a prolonged postoperative course }\end{array}$ & I & $\mathrm{C}$ \\
\hline \multicolumn{3}{|l|}{ 6. Is there any role for local antimicrobials or antiseptics during surgery for IE? } \\
\hline \multicolumn{3}{|l|}{ 7. How should infected areas be drained? } \\
\hline $\begin{array}{l}\text { Whenever feasible, leaving infected areas open to the circulation or the pericardium is optimal from the standpoint of } \\
\text { treating the infection }\end{array}$ & Illb & C \\
\hline \multicolumn{3}{|l|}{ 8. How should operative specimens be handled? } \\
\hline $\begin{array}{l}\text { Operative specimens should be secured for examination by the pathologist to determine presence of organisms and } \\
\text { inflammatory activity }\end{array}$ & I & B \\
\hline $\begin{array}{l}\text { Operative specimens should be used for microbiologic and molecular testing to identify or confirm the pathogens and their } \\
\text { sensitivity to antimicrobial therapy }\end{array}$ & I & A \\
\hline \multicolumn{3}{|l|}{ 9. What is the role of molecular testing with PCR in identifying pathogens? } \\
\hline $\begin{array}{l}\text { Whenever there is clinical suspicion of IE and doubt about the causative organism, molecular testing can be useful to } \\
\text { identify and confirm the pathogens or causative organisms in the operative specimens }\end{array}$ & Ila & $\mathrm{B}$ \\
\hline \multicolumn{3}{|l|}{ 10. What postoperative antimicrobial treatment is required, and for how long should the patient be treated? } \\
\hline $\begin{array}{l}\text { When perioperative cultures and organism sensitivity are known, the antimicrobial regimen and duration of treatment are } \\
\text { reconsidered and decided upon }\end{array}$ & 1 & B \\
\hline $\begin{array}{l}\text { After surgery for active IE, standard duration of postoperative intravenous antimicrobial treatment is } 6 \text { weeks, counted from } \\
\text { the day of surgery, but regimen and duration may be modified and adjusted depending on the organism and its sensitivity to } \\
\text { antimicrobials, treatment response, and pathology }\end{array}$ & Ila & $\mathrm{B}$ \\
\hline For fungal IE, lifelong oral suppressive therapy is reasonable & Ila & B \\
\hline
\end{tabular}

Figure 6 Specific considerations in surgical management of patients with IE. Reproduced from Pettersson GB, Coselli JS, Hussain ST, et al. 2016 American Association for Thoracic Surgery (AATS) Consensus Guidelines: Surgical Treatment of Infective Endocarditis. 7 Thorac Cardiovasc Surg 2017;153:1241-1258.e29, with permission from Elsevier. 
For native aortic valve IE, repair is only occasionally possible. When the disease is invasive reconstruction and root replacement are usually required. Prosthetic valve infections often involve the sewing ring circumferentially. Occasionally the sewing ring is infected, but the infection has not yet penetrated deeper and outside the root. When that is the case and the debridement is adequate, it is possible and feasible to implant another prosthetic valve of choice. However, deeper invasion and destruction of the annulus is more common with aortic PVE. Allograft is certainly the Cleveland Clinic preferred conduit in patients with more extensive and destructive infection.

Fortunately, invasive and destructive disease is less common with mitral than aortic valve IE, and when invasion occurs it is more often shallow. Mitral valve repair is performed whenever possible and a prosthetic annuloplasty ring is added whenever appropriate. When valve replacement is required, a prosthetic valve, either mechanical or tissue, is acceptable, unless there is risk of intracranial bleeding, in which case a tissue valve is preferred. When, however, mitral valve invasion penetrates deeper into the atrioventricular groove, it is much more serious, and radical debridement and sterilization and drainage of the infected area are more difficult. In patients with mitral PVE, the exposure for debridement and removal of the old prosthesis and suture material is worse than for the aortic valve and left ventricular outflow tract. Fortunately, deep invasion into the atrioventricular groove is uncommon, allowing direct implantation of a new prosthesis without additional reconstruction in most cases. When anulus reconstruction is needed, autologous pericardium, bovine pericardium, and other materials can be used. Repair patches must be generous to minimize tension on the suture lines and the valve prosthesis anchored to the ventricular muscle or to the reconstruction patch in a way that prevents leakage and pseudoaneurysm development beneath the prosthesis.

The primary objective of surgery for right-sided IE is most often to eliminate the cause of persistent sepsis and the source of septic emboli to the lung, by radical debridement of infected vegetations and foreign material. Tricuspid valve repair should be attempted whenever possible (50-52). Any prosthetic valve in the tricuspid position is associated with increased risk of recurrent IE, particularly in patients who resume intravenous drug use. Bioprosthetic valves are preferred, although this preference is not based on any comparative studies. With mechanical valves there may be an increased risk of thrombosis and access to the right ventricle and pulmonary artery for catheterization and pacemaker leads is lost.

When distal ascending aorta, hemiarch, or arch replacement is required, a synthetic graft is the standard choice, but a valveless allograft is an alternative in an infected field for replacing the ascending aorta beyond the root. Extending an allograft into the arch may set up a more difficult reoperation if the allograft has had time to calcify. In reoperative surgery, inspection and removal of additional prostheses and vascular grafts, even if not proven to be infected, should be considered and is reasonable if the causative microorganism is $S$. aureus or fungus, provided that the added difficulty and risk is not prohibitive. If it is easy and associated with limited added risk, those implants/ vascular grafts are replaced, whereas if it is difficult and adds to operative risk significantly, they are left alone (53).

\section{Patient with IE and permanent pacemaker systems in place (Figure 5) $(2,3,54,55)$}

Complete removal of pacemaker or defibrillator systems, including all leads and the generator, is indicated as part of the early management plan in patients with IE and likely infection of the device or leads. In patients with right- or left-sided valvular IE caused by $S$. aureus or fungi, complete removal of pacemaker or defibrillator systems is recommended; even without evidence of device or lead infection.

In patients undergoing surgery for IE, removal of leads adds to complexity postoperatively and raises questions if, when, and how the system should be replaced. At the time of surgery for IE, implantation of a new pacemaker system with epicardial leads is a good option when the patient is pacing-dependent and has effective antimicrobial coverage. Placing epicardial leads at the time of surgery is even more attractive in patients at increased risk of becoming reinfected, e.g., those on dialysis, intravenous drug users, or those with ongoing bacteremia at the time of pacemaker removal. However, epicardial leads are not quite as reliable and pacing thresholds are often higher, causing more rapid draining of the pacemaker power supply. A discussion with an electrophysiologist preoperatively may be warranted.

\section{Other considerations in surgical management of patients with IE (Figure 6)}

The AATS emphasize that specimens should be handled properly and divided between pathology and microbiology for microscopy and cultures. Molecular testing with Polymerase Chain Reaction (PCR) should be 


\begin{tabular}{|c|c|c|}
\hline Recommendations & COR & LOE \\
\hline \multicolumn{3}{|l|}{ 1. What is the need for follow-up and additional screening for infectious foci that could cause recurrent infection/IE? } \\
\hline $\begin{array}{l}\text { Primary infectious focus and microorganism portal of entry must be treated during or just after the IE episode, including } \\
\text { follow-up and screening for underlying infectious foci and morbidities }\end{array}$ & 1 & B \\
\hline IE caused by Streptococcus gallolyticus is an indication for colonoscopy within a reasonable time after operation & 1 & B \\
\hline $\begin{array}{l}\text { After surgery for IE, eradication of the pathogen is essential and should be verified by follow-up for } 6 \text { months with an } \\
\text { infectious disease specialist }\end{array}$ & 1 & C \\
\hline $\begin{array}{l}\text { After valve surgery for IE, cure of the infection should be documented by echocardiogram, and the patient should follow up } \\
\text { with a cardiologist }\end{array}$ & I & C \\
\hline \multicolumn{3}{|l|}{ 2. What is the risk of relapse and recurrent IE? } \\
\hline \multicolumn{3}{|l|}{ 3. Should surgical treatment be offered to injection drug users with IE? } \\
\hline $\begin{array}{l}\text { Normal indications for surgery are reasonable to apply to patients who are intravenous drug users. Decision-making must } \\
\text { take the addiction into account, and management must include treatment of the addiction }\end{array}$ & Ila & C \\
\hline \multicolumn{3}{|l|}{ 4. Should surgical treatment be offered to IE patients on dialysis? } \\
\hline $\begin{array}{l}\text { Normal indications for surgery are also reasonable to apply to patients on dialysis, but their additional comorbidity must be } \\
\text { factored into their risk and outcome assessment }\end{array}$ & Ila & C \\
\hline $\begin{array}{l}\text { Patients with renal failure have shorter durability of bioprostheses and allografts because of early calcification, and this may } \\
\text { be considered in the choice of an allograft or a bioprosthesis versus a mechanical valve }\end{array}$ & Ila & B \\
\hline \multicolumn{3}{|l|}{ 5. Should surgical treatment be offered to IE patients with liver cirrhosis? } \\
\hline \multicolumn{3}{|l|}{ 6. Who should get antibiotic prophylaxis for IE? } \\
\hline $\begin{array}{l}\text { Patients who have undergone surgery for IE constitute a high-risk group for recurrent IE and should be recommended for IE } \\
\text { prophylaxis according to guidelines }\end{array}$ & Ilb & B \\
\hline \multicolumn{3}{|l|}{ 7. How should patients with remote IE be managed? } \\
\hline $\begin{array}{l}\text { Normal indications for valve repair or replacement apply to patients with healed or remote IE, but conditions predisposing } \\
\text { for IE should be diagnosed and treated }\end{array}$ & I & $\mathrm{C}$ \\
\hline
\end{tabular}

Figure 7 Surveillance and special considerations for patients with IE. Reproduced from Pettersson GB, Coselli JS, Hussain ST, et al. 2016 American Association for Thoracic Surgery (AATS) Consensus Guidelines: Surgical Treatment of Infective Endocarditis. 7 Thorac Cardiovasc Surg 2017;153:1241-1258.e29, with permission from Elsevier.

considered whenever there is uncertainty regarding the causative microorganism. PCR may identify the causative microorganism in many cases of IE where blood and valve cultures have failed (56-58).

After surgery for active IE, standard duration of postoperative intravenous antimicrobial treatment is 6 weeks, counted from the day of surgery, but regimen and duration may be modified and adjusted depending on the organism and its sensitivity to antimicrobials, treatment response, and pathology. For fungal IE, lifelong oral suppressive therapy is reasonable and used more often.
Long-term, even life-long suppression has also been used in patients with infected vascular grafts and other implant infections. The efficacy of long term suppression has not been well studied.

Other special considerations for patients with IE (Figure 7) The number of patients presenting with IE who are intravenous drug users has increased tremendously over the last decade. Drug addicted patients are younger and have lower surgical risk; the main issue is high risk of relapse and recurrent IE (18). They present with two deadly conditions, 
the IE and the addiction. The guidelines recommend that normal indications for surgery are applied to patients who are intravenous drug users but management must include treatment of the addiction. Access to treatment for addiction is very difficult because of a lack of providers and facilities, and lack of insurance and other means to pay for the scarce resources that may be available

The operative risk for patients on dialysis is higher and long-term outcomes are worse than for patients who are not on dialysis $(59,60)$. Nevertheless, the guidelines still recommend application of normal indications for surgery. Patients with renal failure have shorter durability of bioprostheses and allografts because of early calcification, and this may be considered in the choice of an allograft or a bioprosthesis versus a mechanical valve.

Similarly, in patients with liver cirrhosis, additional comorbidity must be evaluated and factored into their risk and outcome assessment but otherwise normal indications for surgery can be applied. The added operative risk associated with liver cirrhosis is related to its severity, as accessed by the Child-Pugh or Model for End-stage Liver Disease (MELD) score.

\section{Antibiotic prophylaxis for IE}

The AATS guidelines suggest that patients who have undergone surgery for IE constitute a high-risk group for recurrent IE and should be recommended for IE prophylaxis accordingly.

\section{Knowledge gaps}

The most important knowledge gaps relate to timing of surgery in patients with neurological complications, role of early surgery to prevent embolism, and role of early surgical intervention in those with PVE. These are all areas of particular importance, requiring further research.

\section{Acknowledgments}

None.

\section{Footnote}

Conflicts of Interest: The authors have no conflicts of interest to declare.

\section{References}

1. Pettersson GB, Coselli JS, Hussain ST, et al. 2016
American Association for Thoracic Surgery (AATS) Consensus Guidelines: Surgical Treatment of Infective Endocarditis. J Thorac Cardiovasc Surg 2017;153:12411258.e29.

2. Baddour LM, Wilson WR, Bayer AS, et al. Infective endocarditis in adults: diagnosis, antimicrobial therapy, and management of complications: a scientific statement for healthcare professionals from the American Heart Association. Circulation 2015;132:1435-86.

3. Habib G, Lancellotti P, Antunes MJ, et al. 2015 ESC Guidelines for the management of infective endocarditis: The Task Force for the Management of Infective Endocarditis of the European Society of Cardiology (ESC). Endorsed by: European Association for Cardio-Thoracic Surgery (EACTS), the European Association of Nuclear Medicine (EANM). Eur Heart J 2015;36:3075-128.

4. Nishimura RA, Otto CM, Bonow RO, et al. 2014 AHA/ ACC Guideline for the Management of Patients With Valvular Heart Disease: executive summary: a report of the American College of Cardiology/American Heart Association Task Force on Practice Guidelines. Circulation 2014;129:2440-92.

5. Byrne JG, Rezai K, Sanchez JA, et al. Surgical management of endocarditis: the society of thoracic surgeons clinical practice guideline. Ann Thorac Surg 2011;91:2012-9.

6. Gould FK, Denning DW, Elliott TS, et al. Guidelines for the diagnosis and antibiotic treatment of endocarditis in adults: a report of the Working Party of the British Society for Antimicrobial Chemotherapy. J Antimicrob Chemother 2012;67:269-89.

7. Gálvez-Acebal J, Almendro-Delia M, Ruiz J, et al. Influence of early surgical treatment on the prognosis of left-sided infective endocarditis: a multicenter cohort study. Mayo Clin Proc 2014;89:1397-405.

8. Murdoch DR, Corey GR, Hoen B, et al. Clinical presentation, etiology, and outcome of infective endocarditis in the 21st century: the International Collaboration on Endocarditis-Prospective Cohort Study. Arch Intern Med 2009;169:463-73.

9. Cabell CH, Abrutyn E, Fowler VG Jr, et al. Use of surgery in patients with native valve infective endocarditis: results from the International Collaboration on Endocarditis Merged Database. Am Heart J 2005;150:1092-8.

10. Hussain ST, Shrestha NK, Gordon SM, et al. Residual patient, anatomic, and surgical obstacles in treating active left-sided infective endocarditis. J Thorac Cardiovasc Surg 2014;148:981-8. e4.

11. Manne MB, Shrestha NK, Lytle BW, et al. Outcomes 
after surgical treatment of native and prosthetic valve infective endocarditis. Ann Thorac Surg 2012;93:489-93.

12. Thuny F, Grisoli D, Collart F, et al. Management of infective endocarditis: challenges and perspectives. Lancet 2012;379:965-75.

13. Kang DH, Kim YJ, Kim SH, et al. Early surgery versus conventional treatment for infective endocarditis. N Engl J Med 2012;366:2466-73.

14. Habib G, Derumeaux G, Avierinos JF, et al. Value and limitations of the Duke criteria for the diagnosis of infective endocarditis. J Am Coll Cardiol 1999;33:2023-9.

15. Li JS, Sexton DJ, Mick N, et al. Proposed modifications to the Duke criteria for the diagnosis of infective endocarditis. Clin Infect Dis 2000;30:633-8.

16. Pettersson GB, Hussain ST, Shrestha NK, et al. Infective endocarditis: an atlas of disease progression for describing, staging, coding, and understanding the pathology. J Thorac Cardiovasc Surg 2014;147:1142-9.e2.

17. Elgharably H, Hussain ST, Shrestha NK, et al. Current hypotheses in cardiac surgery: biofilm in infective endocarditis. Semin Thorac Cardiovasc Surg 2016;28:56-9.

18. Shrestha NK, Jue J, Hussain ST, et al. Injection drug use and outcomes after surgical intervention for infective endocarditis. Ann Thorac Surg 2015;100:875-82.

19. Houpikian P, Raoult D. Blood culture-negative endocarditis in a reference center: etiologic diagnosis of 348 cases. Medicine (Baltimore) 2005;84:162-73.

20. Dickerman SA, Abrutyn E, Barsic B, et al. The relationship between the initiation of antimicrobial therapy and the incidence of stroke in infective endocarditis: an analysis from the ICE Prospective Cohort Study (ICE-PCS). Am Heart J 2007;154:1086-94.

21. Hubert S, Thuny F, Resseguier N, et al. Prediction of symptomatic embolism in infective endocarditis: construction and validation of a risk calculator in a multicenter cohort. J Am Coll Cardiol 2013;62:1384-92.

22. Thuny F, Di Salvo G, Belliard O, et al. Risk of embolism and death in infective endocarditis: prognostic value of echocardiography: a prospective multicenter study. Circulation 2005;112:69-75.

23. Cooper HA, Thompson EC, Laureno R, et al. Subclinical brain embolization in left-sided infective endocarditis: results from the evaluation by MRI of the brains of patients with left-sided intracardiac solid masses (EMBOLISM) pilot study. Circulation 2009;120:585-91.

24. Barsic B, Dickerman S, Krajinovic V, et al. Influence of the timing of cardiac surgery on the outcome of patients with infective endocarditis and stroke. Clin Infect Dis
2013;56:209-17.

25. Botelho-Nevers E, Thuny F, Casalta JP, et al. Dramatic reduction in infective endocarditis-related mortality with a management-based approach. Arch Intern Med 2009;169:1290-8.

26. Funakoshi S, Kaji S, Yamamuro A, et al. Impact of early surgery in the active phase on long-term outcomes in left-sided native valve infective endocarditis. J Thorac Cardiovasc Surg 2011;142:836-842.e1.

27. Prendergast BD, Tornos P. Surgery for infective endocarditis: who and when? Circulation 2010;121:1141-52.

28. Bedeir K, Reardon M, Ramlawi B. Infective endocarditis: perioperative management and surgical principles. J Thorac Cardiovasc Surg 2014;147:1133-41.

29. Attaran S, Chukwuemeka A, Punjabi PP, et al. Do all patients with prosthetic valve endocarditis need surgery? Interact Cardiovasc Thorac Surg 2012;15:1057-61.

30. Habib G, Avierinos JF, Thuny F. Aortic valve endocarditis: is there an optimal surgical timing? Curr Opin Cardiol 2007;22:77-83.

31. Thuny F, Beurtheret S, Mancini J, et al. The timing of surgery influences mortality and morbidity in adults with severe complicated infective endocarditis: a propensity analysis. Eur Heart J 2011;32:2027-33.

32. Alonso-Valle H, Farinas-Alvarez C, Garcia-Palomo JD, et al. Clinical course and predictors of death in prosthetic valve endocarditis over a 20 -year period. J Thorac Cardiovasc Surg 2010;139:887-93.

33. Thuny F, Avierinos JF, Tribouilloy C, et al. Impact of cerebrovascular complications on mortality and neurologic outcome during infective endocarditis: a prospective multicentre study. Eur Heart J 2007;28:1155-61.

34. García-Cabrera E, Fernandez-Hidalgo N, Almirante B, et al. Neurological complications of infective endocarditis: risk factors, outcome, and impact of cardiac surgery: a multicenter observational study. Circulation 2013;127:2272-84.

35. Eishi K, Kawazoe K, Kuriyama Y, et al. Surgical management of infective endocarditis associated with cerebral complications. Multi-center retrospective study in Japan. J Thorac Cardiovasc Surg 1995;110:1745-55.

36. Chu VH, Park LP, Athan E, et al. Association between surgical indications, operative risk, and clinical outcome in infective endocarditis: a prospective study from the International Collaboration on Endocarditis. Circulation 2015;131:131-40.

37. Sorabella RA, Han SM, Grbic M, et al. Early operation for endocarditis complicated by preoperative cerebral emboli 
is not associated with worsened outcomes. Ann Thorac Surg 2015;100:501-8.

38. Okita Y, Minakata K, Yasuno S, et al. Optimal timing of surgery for active infective endocarditis with cerebral complications: a Japanese multicentre study. Eur J Cardiothorac Surg 2016;50:374-82.

39. Yoshioka D, Toda K, Sakaguchi T, et al. Valve surgery in active endocarditis patients complicated by intracranial haemorrhage: the influence of the timing of surgery on neurological outcomes. Eur J Cardiothorac Surg 2014;45:1082-8.

40. Misfeld M, Girrbach F, Etz CD, et al. Surgery for infective endocarditis complicated by cerebral embolism: a consecutive series of 375 patients. J Thorac Cardiovasc Surg 2014;147:1837-44.

41. Ruttmann E, Legit C, Poelzl G, et al. Mitral valve repair provides improved outcome over replacement in active infective endocarditis. J Thorac Cardiovasc Surg 2005;130:765-71.

42. Muehrcke DD, Cosgrove DM 3rd, Lytle BW, et al. Is there an advantage to repairing infected mitral valves? Ann Thorac Surg 1997;63:1718-24.

43. Jassar AS, Bavaria JE, Szeto WY, et al. Graft selection for aortic root replacement in complex active endocarditis: does it matter? Ann Thorac Surg 2012;93:480-7.

44. Kim JB, Ejiofor JI, Yammine M, et al. Are homografts superior to conventional prosthetic valves in the setting of infective endocarditis involving the aortic valve? J Thorac Cardiovasc Surg 2016;151:1239-46, 1248.e1-2.

45. Savage EB, Saha-Chaudhuri P, Asher CR, et al. Outcomes and prosthesis choice for active aortic valve infective endocarditis: analysis of the Society of Thoracic Surgeons Adult Cardiac Surgery Database. Ann Thorac Surg 2014;98:806-14.

46. Sabik JF, Lytle BW, Blackstone EH, et al. Aortic root replacement with cryopreserved allograft for prosthetic valve endocarditis. Ann Thorac Surg 2002;74:650-9; discussion 659.

47. Musci M, Weng Y, Hubler M, et al. Homograft aortic root replacement in native or prosthetic active infective endocarditis: twenty-year single-center experience. J Thorac Cardiovasc Surg 2010;139:665-73.

48. Pettersson GB, Hussain ST, Ramankutty RM, et al. Reconstruction of fibrous skeleton: technique, pitfalls and results. Multimed Man Cardiothorac Surg 2014. doi: $10.1093 / \mathrm{mmcts} / \mathrm{mmu} 004$.

49. Davierwala PM, Binner C, Subramanian S, et al. Double valve replacement and reconstruction of the intervalvular fibrous body in patients with active infective endocarditis. Eur J Cardiothorac Surg 2014;45:146-52.

50. Gaca JG, Sheng S, Daneshmand M, et al. Current outcomes for tricuspid valve infective endocarditis surgery in North America. Ann Thorac Surg 2013;96:1374-81.

51. Dawood MY, Cheema FH, Ghoreishi M, et al. Contemporary outcomes of operations for tricuspid valve infective endocarditis. Ann Thorac Surg 2015;99:539-46.

52. Witten JC, Hussain ST, Shrestha NK, et al. Surgical Treatment of Right-sided Infective Endocarditis. J Thorac Cardiovasc Surg 2019;157:1418-1427.e14.

53. LeMaire SA, Coselli JS. Options for managing infected ascending aortic grafts. J Thorac Cardiovasc Surg 2007;134:839-43.

54. Baddour LM, Epstein AE, Erickson CC, et al. Update on cardiovascular implantable electronic device infections and their management: a scientific statement from the American Heart Association. Circulation 2010;121:458-77.

55. Baddour LM, Cha YM, Wilson WR. Clinical practice. Infections of cardiovascular implantable electronic devices. N Engl J Med 2012;367:842-9.

56. Shrestha NK, Ledtke CS, Wang H, et al. Heart valve culture and sequencing to identify the infective endocarditis pathogen in surgically treated patients. Ann Thorac Surg 2015;99:33-7.

57. Fournier PE, Thuny F, Richet H, et al. Comprehensive diagnostic strategy for blood culture-negative endocarditis: a prospective study of 819 new cases. Clin Infect Dis 2010;51:131-40.

58. Fedoruk LM, Jamieson WR, Ling H, et al. Predictors of recurrence and reoperation for prosthetic valve endocarditis after valve replacement surgery for native valve endocarditis. J Thorac Cardiovasc Surg 2009;137:326-33.

59. Leither MD, Shroff GR, Ding S, et al. Long-term survival of dialysis patients with bacterial endocarditis undergoing valvular replacement surgery in the United States. Circulation 2013;128:344-51.

60. Raza S, Hussain ST, Rajeswaran J, et al. Value of Surgery for Infective Endocarditis in Dialysis Patients. J Thorac Cardiovasc Surg 2017;154:61-70.e6.

Cite this article as: Pettersson GB, Hussain ST. Current AATS guidelines on surgical treatment of infective endocarditis. Ann Cardiothorac Surg 2019;8(6):630-644. doi: 10.21037/ acs.2019.10.05 